\title{
Health Providers and Recommended Family Planning Guidelines in Benin
}

\author{
Jacques W. Saïzonou ${ }^{1,2}$, Alphonse M. Affo ${ }^{2,3, *}$, Virginie Mongbo ${ }^{1}$, Robert Zannou ${ }^{4}$, Patrick Makoutodé ${ }^{1}$, \\ Alphonse Kpozèhouen ${ }^{1}$, Thierry Tossou Boco ${ }^{5}$, Soulemane Zan $^{5}$, Léopold Ouédraogo ${ }^{6}$, \\ Edgard-Marius Ouendo ${ }^{1}$

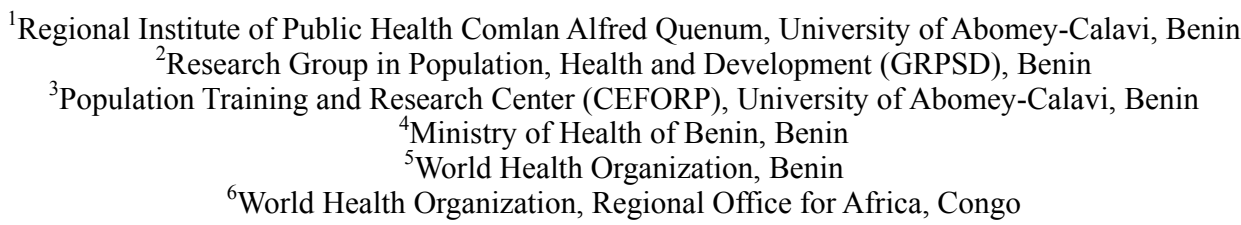

Received January 6, 2021; Revised April 13, 2021; Accepted May 10, 2021

\section{Cite This Paper in the following Citation Styles}

(a): [1] Jacques W. Saïzonou, Alphonse M. Affo, Virginie Mongbo, Robert Zannou, Patrick Makoutodé, Alphonse Kpozèhouen, Thierry Tossou Boco, Soulemane Zan, Léopold Ouédraogo, Edgard-Marius Ouendo , "Health Providers and Recommended Family Planning Guidelines in Benin," Universal Journal of Public Health, Vol. 9, No. 3, pp. 103 112, 2021. DOI: 10.13189/ujph.2021.090301.

(b): Jacques W. Saïzonou, Alphonse M. Affo, Virginie Mongbo, Robert Zannou, Patrick Makoutodé, Alphonse Kpozèhouen, Thierry Tossou Boco, Soulemane Zan, Léopold Ouédraogo, Edgard-Marius Ouendo (2021). Health Providers and Recommended Family Planning Guidelines in Benin. Universal Journal of Public Health, 9(3), 103 - 112. DOI: 10.13189/ujph.2021.090301.

Copyright $\mathrm{O} 2021$ by authors, all rights reserved. Authors agree that this article remains permanently open access under the terms of the Creative Commons Attribution License 4.0 International License

\begin{abstract}
Despite global commitments of policy makers to improve maternal health through capacity strengthening and provision of high-quality reproductive health services, family planning services still face great challenges in Africa. A nationwide cross-sectional study conducted in 2019 in Benin involving health facilities showed gaps in Knowledge Attitudes and Practices (KAP) in meeting family planning guidelines. A total of 446 health providers were interviewed. Data analysis relied on the calculation of tertiles and chi-square tests were computed to assess the differences at 5\% level of significance. Results reveal that most health providers $(92.9 \%)$ showed a good knowledge of the standard guidelines of FP, one fourth (23.4\%) showed a wrong knowledge of the advantages and about half $(51.6 \%)$ of them lacked extended knowledge of FP methods. Results also underscore discrepancies between most providers' attitudes and existing FP guidelines which were in line with the inadequate practices showed by half of respondents. Results underscore the need for the development and implementation of basic training programs and capacity strengthening interventions toward health providers in
\end{abstract}

order to improve performances of FP services in Benin.

Keywords Benefits, Family Planning, Guidelines, Training

\section{Introduction}

Every year, nearly 800,000 women of childbearing age die from pregnancy, childbirth and postpartum complications worldwide [1]. The African continent, particularly sub-Saharan Africa, has the highest maternal mortality ratio (MMR) worldwide, equivalent to 2.5 times the global MMR and 38 times that of high-income countries [2-4]. The direct causes of these deaths, most of which are preventable, are haemorrhages, eclampsia, infections, and complications of abortion. Indirect causes contribute to $30 \%$ of these deaths [5]. Family Planning (FP) has been proven to be one of the most effective strategies for reducing maternal mortality. It is an essential or primary prevention strategy that is effective in reducing 
maternal deaths from induced abortion [6]. Although relatively high globally, the contraceptive prevalence rate is low in West Africa and shows great disparities. In 2015 it was $64 \%$ globally, $71 \%$ in low- and middle-income countries, $63 \%$ in high-income countries and $28 \%$ in West Africa [7]. According to Benin Demographic and Health Surveys, modern contraceptive prevalence rate among women aged between 15 and 49 years living in union increased from $3 \%$ in 1996 to $6 \%$ in $2006,8 \%$ in 2011-2012 and $12 \%$ in 2017-2018. Despite this gradual improvement, FP remains underutilized, with $32 \%$ of unmet need in 2017-2018 [8]. This reflects the situation in most sub-Saharan African countries over the last two decades, where overall contraceptive demand is about $36 \%$ to $45 \%$, compared to a satisfaction rate of $5 \%$ to $12 \%$ [9].

Determinants of low contraceptive use include: the quality of services provided by health care providers, lack of information or counselling, lack of confidentiality, requirement of spousal or parental permission, high cost of services, accessibility (geographic and economic) to health facilities, limited choice of contraceptive methods, inconvenient opening hours, discomfort and difficulty in use, partner opposition, fear of social disapproval, and side effects $[7,10]$.

Faced with this situation of low utilization, several interventions have been initiated in Benin, such as the development of FP guidelines, strengthening providers' skills, securing contraceptive products, awareness and FP delivery campaigns, etc. $[7,10]$. This package of interventions has probably contributed to some improvement in the use of FP services.

Although the stakes of the "safe motherhood" advocated by the public authorities in Benin are concerned with the supply and demand side of sexual and reproductive health services, this article focuses on the supply-side particularly FP services, which is relatively under-documented in Benin even though it appears to be as important as the demand to guarantee responsible sexual and reproductive health of the population. The paper aimed at identifying and examining the gaps in knowledge, attitudes and practices of service providers in reducing high maternal mortality rates in Benin.

Within the framework of RH/FP service delivery, there are guidelines for training health care providers to meet the RH/FP needs of the population. These requirements from health care providers are primarily underpinned by their KAP regarding the RH/FP guidelines around which they are expected to be trained. The main limitation of such approach is the availability of quality SR/PF inputs or products and their accessibility to anyone who wishes to benefit from them. But to move forward in the care pathways, providers need to have levels of knowledge and practice that are consistent with the guidelines in their sector.

Benin's national FP policy aimed to equip health providers with necessary skills to master the country' fertility reduction strategies in order to increase their productivity to contribute to the country's sustainable development. Family planning, delivery assisted by skilled health personnel, emergency obstetric and neonatal care, was well documented to be the key pillars for the maternal and neonatal reduction. However, related indicators still showed major gaps. Key causes identified were: the low availability of contraceptives at the service delivery points, the lack of qualified health personnel for service delivery, and the insufficient quality of FP services. To fill these gaps, Benin's Ministry of Health set up an effective training tool package commonly called standard guidelines in FP. It aimed at educating health providers on training and provision methods in contraceptive technology in order to get them adapt to development in the field [10]. We found it useful to review health providers' understanding in the implementation of the standard guidelines.

\section{Materials and Methods}

\subsection{Type of Study, Sampling and Data Collection Technique}

The study used secondary data collected by the Institut Régional de Santé Publique Comlan Alfred Quenum (IRSP/CAQ) on behalf of the Country Office of the World Health Organization and the Ministry of Health in July 2019 [11]. The data was based on KAP of health providers on Family Planning (FP) and abortion care in Benin. From the database, FP data were extracted from the corpus of the present analyses. A section of the questionnaire collected information on the availability of SRH/FP services and the KAP of health care providers. The target population considered was composed of all the FP health care providers operating in the health facilities investigated. They were mainly midwives, nurses and health care assistants. Medical Doctors and other SRH/FP specialists were interviewed using an interview guide. The study took place at all levels of the health care system in Benin. The reference hospitals (CNHU-HKM and CHU-MEL) were selected at the national level. At the intermediate level, all five Departmental Hospital Centres (CHD) were selected. At the peripheral level, Benin's 34 health zones have been targeted. In each health zone, the Zone Hospital was selected. In addition, two Commune Health Centres (CSCs), two District Health Centres (DHCs), and two private clinics/clinics were randomly selected.

\subsection{Analysis of the Data}

The data collected on paper were entered under Epidata and analysed with Stata 11. Central tendency and dispersion parameters were used to compute some indicators. The Knowledge and Attitudes (KA) of health 
care providers were assessed with composite indicators from the FP guidelines of the Ministry of Health [12] which served as a reference for the study. A composite indicator of in-depth FP knowledge was defined, gathering the knowledge of FP methods as well as the specific side effects associated with each method. The tertiles of the indicators were used as a threshold for assessing KA. Thus, a health care provider is considered with a "very good KA" if the average value of his scores is greater than or equal to the $2^{\text {nd }}$ tertile; a "good $\mathrm{KA}$ " if the average value of the scores is between the $1^{\text {st }}$ tertile and the $2^{\text {nd }}$ tertile and a "bad KA" if this value is less than the $1^{\text {st }}$ tertile. With regard to practices, all useful gestures required by national reproductive health guidelines were considered. Therefore, a provider has a good FP practice if he/she complies with the required FP guidelines. In all other cases, the provider's FP practice is poor. The Chi-Square test of independence was employed to determine if there is a significant relationship between each independent variable and the dependent variable. The null hypothesis (H0) for Chi-Square assumes that there is no association between the two variables while the alternative hypothesis (H1) assumes that there is an association between the two variables. For example, to examine whether health providers' attitudes towards major side effects is significantly associated with their education level, the null hypothesis should be "There is no association between health providers' attitudes toward major side effects and their education level" while the alternative hypothesis would be "health providers' attitudes toward major side effects is significantly associated with their education level". The critical value for the chi-square statistic determined by the level of significance is set $5 \%$ in this study. The null hypothesis is accepted if the computed statistic is greater than the level of significance and rejected (meaning $\mathrm{H} 1$ is accepted) otherwise (see appendix for some screenshots for statistical analyses).

\section{Results}

\subsection{Profile of Respondents}

A total of 446 FP providers were surveyed. As shown in Table 1, the majority of respondents were midwives $(74.7 \%)$, with an average age of $38.0 \pm 8.5$ years. More than half of them $(57.2 \%)$ had high school education and $41.9 \%$ higher education, and $68.4 \%$ were living in urban areas.
Table 1. Socio-demographic characteristics of respondents to the KAP survey on FP in Benin in $2019(n=446)$

\begin{tabular}{|c|c|c|c|}
\hline Variables & Categories & Percentage & $\begin{array}{l}\text { Numbers of } \\
\text { respondents }\end{array}$ \\
\hline \multirow{3}{*}{ Sex } & Female & 95.5 & 426 \\
\hline & Male & 4.0 & 18 \\
\hline & No specified & 0.5 & 2 \\
\hline \multirow{5}{*}{ Age (in year) } & $<25$ & 5.2 & 23 \\
\hline & $25-34$ & 26.5 & 118 \\
\hline & $35-44$ & 50.0 & 223 \\
\hline & 45 et + & 17.9 & 80 \\
\hline & No specified & 0.5 & 2 \\
\hline \multirow{3}{*}{ Education level } & High School & 57.2 & 255 \\
\hline & $\begin{array}{c}\text { Tertiary } \\
\text { Education }\end{array}$ & 41.9 & 187 \\
\hline & Not specified & 0.9 & 4 \\
\hline \multirow{6}{*}{ Qualification } & Midwives & 74.7 & 333 \\
\hline & Surgeons & 0.2 & 1 \\
\hline & $\begin{array}{c}\text { General } \\
\text { practitioner }\end{array}$ & 0.2 & 1 \\
\hline & Certified nurse & 7.9 & 35 \\
\hline & Health nurse & 10.3 & 46 \\
\hline & $\begin{array}{c}\text { Health care } \\
\text { assistants }\end{array}$ & 6.7 & 30 \\
\hline \multirow{3}{*}{$\begin{array}{l}\text { Place of } \\
\text { residence }\end{array}$} & Rural & 29.2 & 130 \\
\hline & Urban & 68.4 & 305 \\
\hline & Not specified & 2.5 & 11 \\
\hline
\end{tabular}

\subsection{Training on Family Planning}

Figure 1 showed the distribution of respondents who were reported to have or not have received FP training. It shows that half $(51 \%)$ of the claimants surveyed had not received any training in FP in the preceding three years of the survey.

\subsection{Service Providers' Knowledge of FP}

The knowledge of the health providers surveyed on FP rights, components, stages and benefits of FP is summarized in Figure 2. This figure shows that knowledge on the different aspects of FP was good overall and more specifically in terms of knowledge of FP components $(92.9 \%)$, stages $(85.5 \%)$, benefits $(76.6 \%)$ and FP rights $(77.1 \%)$. Providers in health centres had better knowledge of FP stages than those in hospitals $(p=0.005)$. 


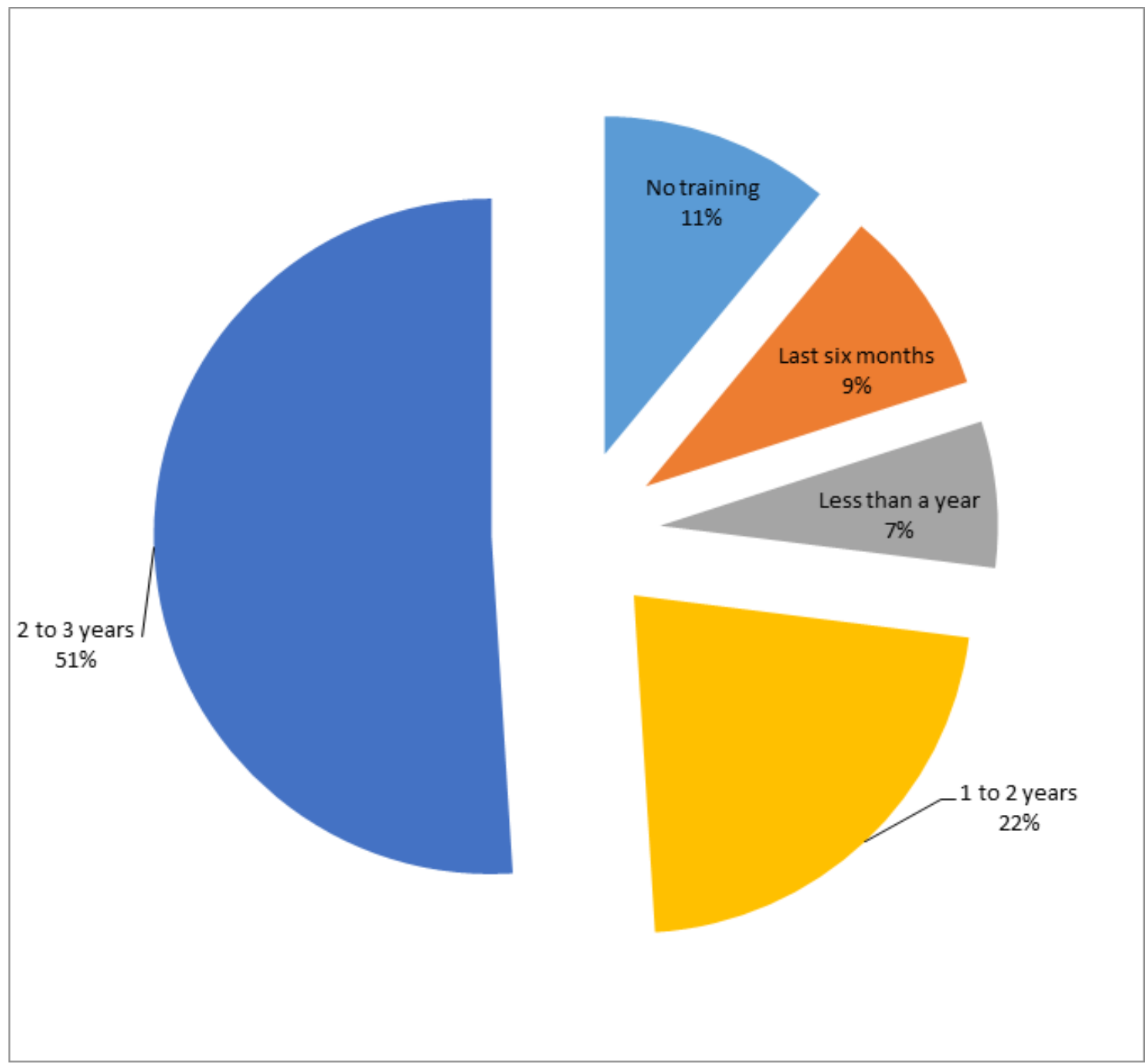

Figure 1. Distribution (\%) of respondents who have or have not received FP training in the last three years in Benin's 34 Health zone in 2019

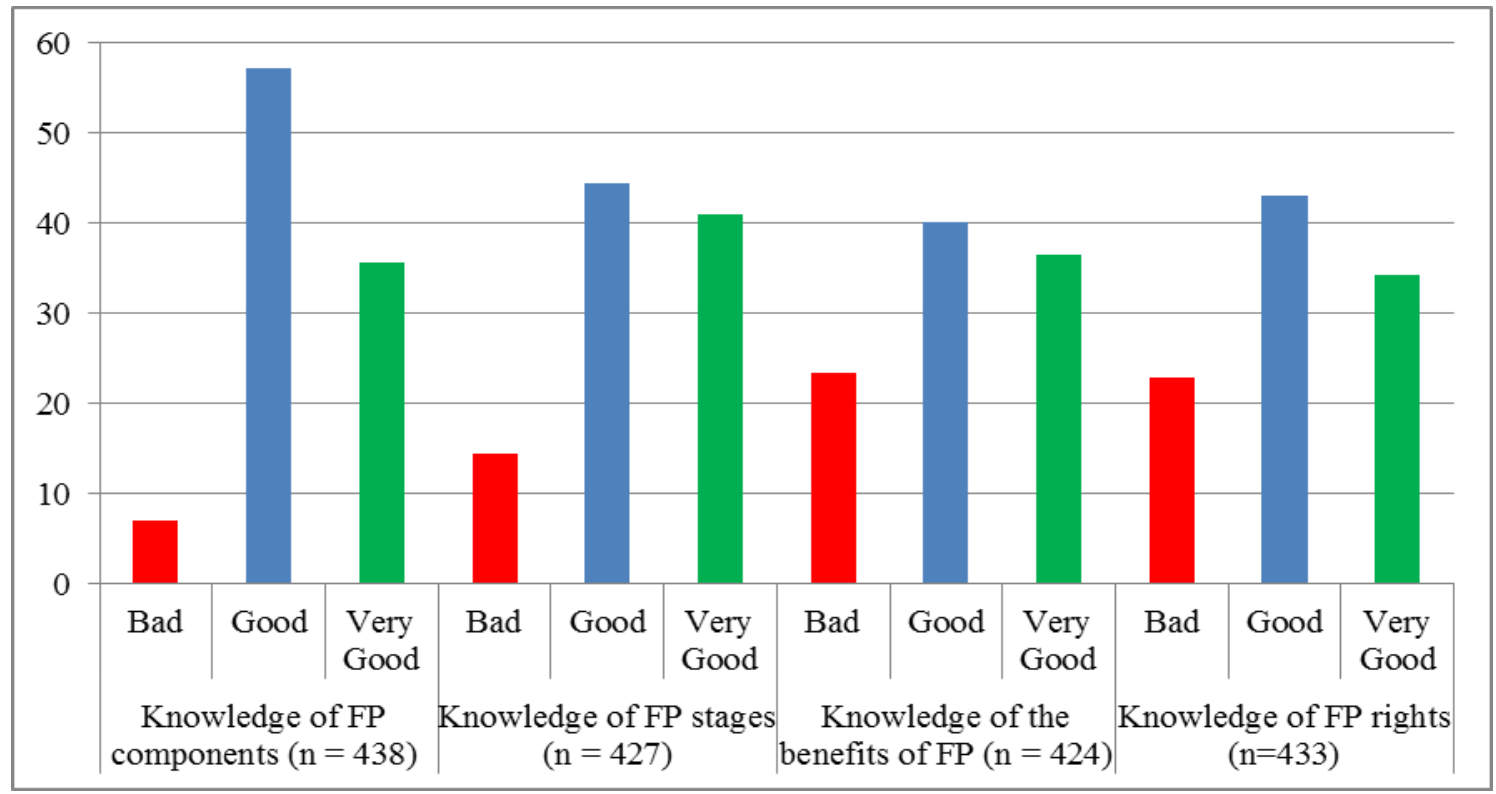

Figure 2. Distribution (\%) of providers according to their knowledge of different aspects of FP in Benin in 2019 


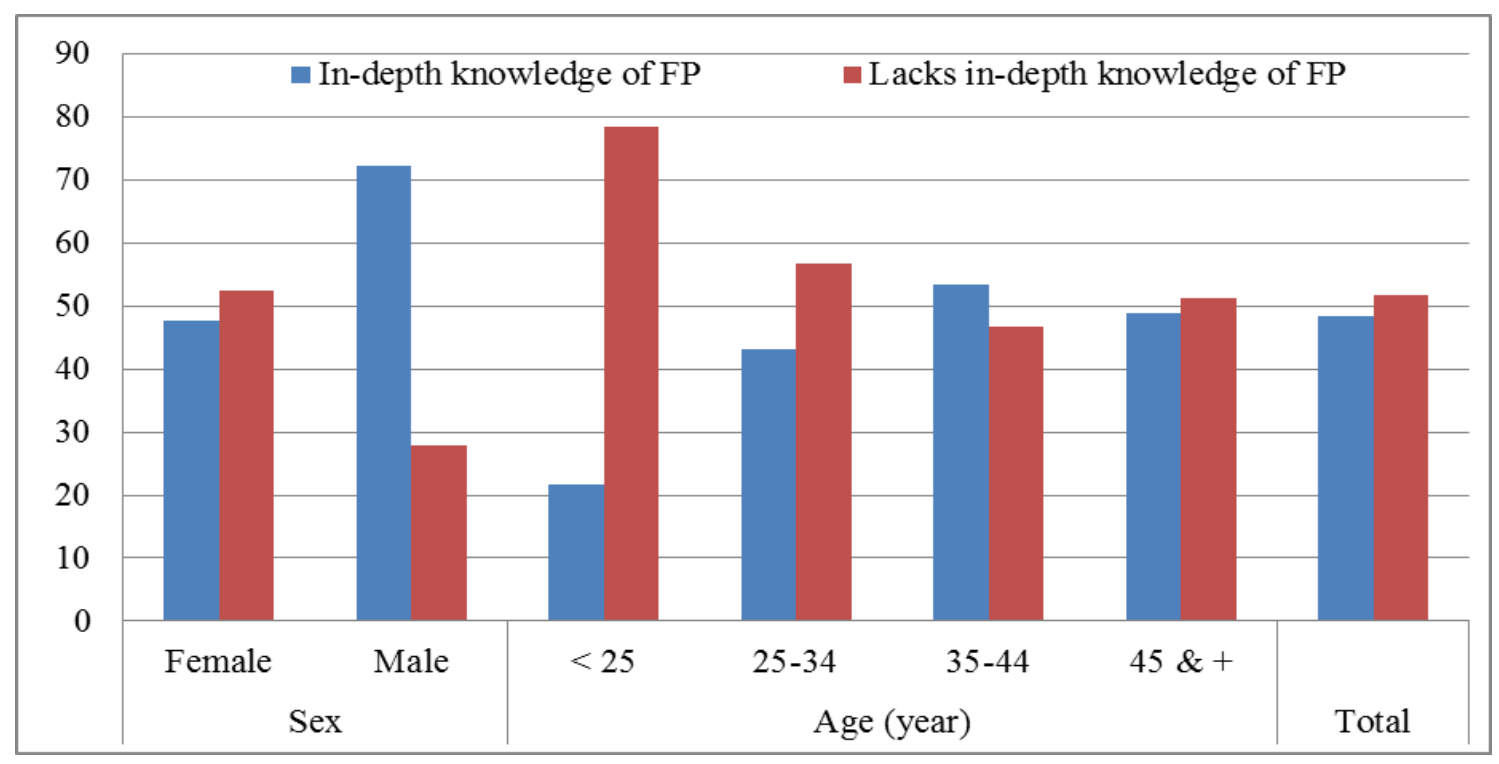

Figure 3. Distribution (\%) of providers according to their in-depth knowledge of FP methods in Benin toward sex and age in 2019

Table 2. Distribution of providers according to their attitudes in different FP situations in Benin in 2019

\begin{tabular}{|c|c|c|c|c|c|c|c|c|c|c|}
\hline \multirow{2}{*}{$\begin{array}{l}\text { Characteristics of } \\
\text { healthcare } \\
\text { providers }\end{array}$} & \multicolumn{2}{|c|}{$\begin{array}{c}\text { Systematically } \\
\text { recommend } \\
\text { postpartum FP } \\
(\mathrm{n}=441)[95 \% \mathrm{CI}] \\
\end{array}$} & \multicolumn{2}{|c|}{$\begin{array}{c}\text { Systematically } \\
\text { offers post-abortion } \\
\text { FP } \\
(\mathrm{n}=442)[95 \% \mathrm{CI}]\end{array}$} & \multicolumn{2}{|c|}{$\begin{array}{c}\text { Attitude towards minor } \\
\text { side effects } \\
(\mathrm{n}=413)[95 \% \mathrm{CI}]\end{array}$} & \multicolumn{2}{|c|}{$\begin{array}{l}\text { Attitude towards } \\
\text { major side effects } \\
(\mathrm{n}=400)[95 \% \mathrm{CI}]\end{array}$} & \multicolumn{2}{|c|}{$\begin{array}{c}\text { Attitude towards a } \\
\text { client at risk of STI / } \\
\text { HIV / AIDS }(n=434) \\
{[95 \% \mathrm{CI}]}\end{array}$} \\
\hline & No (\%) & Yes $(\%)$ & No (\%) & Yes $(\%)$ & $\operatorname{Bad}(\%)$ & Good (\%) & $\operatorname{Bad}(\%)$ & $\begin{array}{c}\text { Good } \\
(\%)\end{array}$ & $\operatorname{Bad}(\%)$ & Good (\%) \\
\hline $\operatorname{Sex}$ & \multicolumn{2}{|c|}{$\begin{array}{c}P=0.043[0.25- \\
7.94]\end{array}$} & \multicolumn{2}{|c|}{$\begin{array}{c}P=0.890[-2.36- \\
2.40]\end{array}$} & \multicolumn{2}{|c|}{$P=0.200[-2.24-5.52]$} & \multicolumn{2}{|c|}{$P=0.144[1.53-2.73]$} & \multicolumn{2}{|c|}{$\begin{array}{c}P=0.752[-2.13- \\
2.33]\end{array}$} \\
\hline Female & 42.5 & 57.5 & 48.3 & 51.7 & 71.1 & 28.9 & 86.7 & 12.3 & 73.0 & 27.0 \\
\hline Male & 66.7 & 33.3 & 50.0 & 50.0 & 56.3 & 43.8 & 100.0 & 0.0 & 76.5 & 23.5 \\
\hline Age (year) & \multicolumn{2}{|c|}{$\begin{array}{c}P=0.750[-3.71- \\
6.14]\end{array}$} & \multicolumn{2}{|c|}{$\begin{array}{c}P=0.374[-2.22- \\
8.46]\end{array}$} & \multicolumn{2}{|c|}{$P=0.755[-4.03-6.42]$} & \multicolumn{2}{|c|}{$\begin{array}{c}P=0.895[-4.06- \\
5.27]\end{array}$} & \multicolumn{2}{|c|}{$\begin{array}{c}P=0.089[0.55- \\
12.47]\end{array}$} \\
\hline$<25$ & 43.5 & 56.5 & 34.8 & 65.2 & 61.9 & 38.1 & 90.0 & 10.0 & 82.6 & 17.4 \\
\hline $25-34$ & 45.7 & 54.3 & 53.5 & 46.6 & 73.2 & 26.9 & 88.2 & 11.8 & 79.3 & 20.7 \\
\hline $35-44$ & 43.9 & 56.1 & 47.3 & 52.7 & 70.4 & 29.6 & 87.7 & 12.3 & 71.5 & 28.5 \\
\hline 45 et + & 38.0 & 62.0 & 50.6 & 49.4 & 72.4 & 27.6 & 84.9 & 15.1 & 64.6 & 35.4 \\
\hline Education level & \multicolumn{2}{|c|}{$\begin{array}{c}P=0.118[-1.27- \\
6.16]\end{array}$} & \multicolumn{2}{|c|}{$\begin{array}{c}P=0.124[-1.61- \\
6.34]\end{array}$} & \multicolumn{2}{|c|}{$P=0.631[-2.47-2.94]$} & \multicolumn{2}{|c|}{$\begin{array}{c}P=0.081[-2.32- \\
4.06]\end{array}$} & \multicolumn{2}{|c|}{$\begin{array}{c}P=0.463[-2.49- \\
3.56]\end{array}$} \\
\hline High School & 46.6 & 53.4 & 45.3 & 54.7 & 70.0 & 30.0 & 88.7 & 11.3 & 74.6 & 25.4 \\
\hline Tertiary Education & 39.1 & 60.9 & 52.7 & 47.3 & 72.2 & 27.8 & 85.5 & 14.5 & 71.4 & 28.6 \\
\hline Qualification & \multicolumn{2}{|c|}{$\begin{array}{c}P=0.033[0-22- \\
7.97]\end{array}$} & \multicolumn{2}{|c|}{$\begin{array}{c}\mathrm{P}=0.457[-0.68- \\
9.96]\end{array}$} & \multicolumn{2}{|c|}{$P=0.568[-2.11-8.64]$} & \multicolumn{2}{|c|}{$P=0.471[0.26-7.53]$} & \multicolumn{2}{|c|}{$\begin{array}{c}P=0.307[-0.94- \\
12.91]\end{array}$} \\
\hline Midwives & 40.3 & 59.7 & 48.9 & 51.1 & 70.6 & 29.5 & 85.4 & 14.6 & 74.4 & 25.6 \\
\hline Surgeon & 0.0 & 100.0 & 100.0 & 0.0 & 0.0 & 100.0 & 100.0 & 0.0 & 0.0 & 100.0 \\
\hline $\begin{array}{c}\text { General } \\
\text { Practitioner }\end{array}$ & 100.0 & 0.0 & 100.0 & 0.0 & - & - & - & - & 100.0 & 0.0 \\
\hline Certified nurse & 54.3 & 45.7 & 40.0 & 60.0 & 75.8 & 24.2 & 93.8 & 6.3 & 71.4 & 28.6 \\
\hline Health nurse & 42.2 & 57.8 & 55.6 & 44.4 & 72.7 & 27.3 & 92.5 & 7.5 & 72.1 & 27.9 \\
\hline $\begin{array}{l}\text { Health care } \\
\text { assistant }\end{array}$ & 65.5 & 34.5 & 41.4 & 58.6 & 65.4 & 34.6 & 92.3 & 7.7 & 60.0 & 40.0 \\
\hline Type of facility & \multicolumn{2}{|c|}{$\begin{array}{c}\mathrm{P}=0.168[-147- \\
8.61]\end{array}$} & \multicolumn{2}{|c|}{$\begin{array}{c}P=0.622[-3.30- \\
5.20]\end{array}$} & \multicolumn{2}{|c|}{$\mathrm{P}=0.198[-1.45-7.92]$} & \multicolumn{2}{|c|}{$\begin{array}{c}P=0.542[-2.59- \\
5.04]\end{array}$} & $\mathrm{P}=0.289$ & $2-7.39]$ \\
\hline Hospital & 38.8 & 61.2 & 50.7 & 49.3 & 76.8 & 23.2 & 89.9 & 10.1 & 76.5 & 23.5 \\
\hline $\begin{array}{c}\text { Private/confessiona } \\
1 \text { clinic } \\
\end{array}$ & 38.0 & 62.0 & 43.7 & 56.3 & 68.8 & 31.2 & 87.5 & 12.5 & 66.2 & 33.8 \\
\hline Health centres & 47.5 & 52.5 & 48.9 & 51.1 & 67.9 & 32.1 & 85.7 & 14.3 & 72.7 & 27.3 \\
\hline Place of residence & $\begin{array}{r}P=0.702 \\
2.8\end{array}$ & $\begin{array}{l}{[-2.57-} \\
6]\end{array}$ & $\begin{array}{r}P=0.04 \\
8 \\
\end{array}$ & $\begin{array}{l}{[-0.45-} \\
6]\end{array}$ & $P=0.076$ & $0-7.10]$ & $\begin{array}{r}P=0.18 \\
4 .\end{array}$ & $0.97-$ & $\begin{array}{r}P=0.35 \\
3 .\end{array}$ & $\begin{array}{l}-2.11- \\
4]\end{array}$ \\
\hline Rural & 44.2 & 55.8 & 55.8 & 44.2 & 76.7 & 23.3 & 91.2 & 8.9 & 76.2 & 23.8 \\
\hline Urban & 42.2 & 57.8 & 45.0 & 55.0 & 67.8 & 32.2 & 86.3 & 13.7 & 71.8 & 28.2 \\
\hline Total & 43.3 & 56.7 & 48.6 & 51.4 & 70.7 & 29.3 & 87.3 & 12.8 & 72.8 & 27.2 \\
\hline
\end{tabular}


Overall, half (51.6\%) of the providers surveyed did not have in-depth knowledge of FP methods. Knowledge of FP methods was significantly associated with claimant gender and age $(\mathrm{p}<.05$ respectively). Claimants under 35 years old were more affected by the lack of familiarity with family planning methods (Figure 3).

\subsection{Service Providers' Attitudes towards FP}

Provider attitudes toward the side effects of FP and toward a postpartum or post-abortion client are presented in Table 2. Positive FP attitudes ranged from $12.8 \%$ for managing major side effects to $56.7 \%$ for routinely recommending postpartum FP. Systematic FP referral in postpartum was associated with gender $(\mathrm{p}=0.043)$ and provider qualification $(\mathrm{p}=0.033)$, whereas in post-abortion it was associated with place of residence ( $p$ $=0.040)$.

\subsection{FP Practices}

Provider practice in various aspects of FP was generally low. The best practices observed concerned information, education, and communication (IEC) strategies (87.0\%) and counselling (89.6\%) (Figure 4).

\section{Discussion}

The good knowledge recorded on the different aspects of
FP is certainly encouraging, but insufficient for quality service delivery and misleading in terms of identifying capacity building needs. Indeed, in-depth knowledge is the basis for right attitudes and adequate practices of providers [13]. Thus, the fact that only half of the providers have a good in-depth knowledge of FP justifies the low level of FP attitudes and practices recorded. This low level of in-depth knowledge of FP could pose the problem of training and/or supervision of providers. Indeed, even if FP is an integral part of the providers' training curriculum, it is normal that training sessions are regularly organized for them. However, $11 \%$ of the respondents have not received any training in the last three years and 51\% received FP training within the preceding two years of the survey. In the absence of training sessions, well-organized training supervision could have improved the FP providers' level of FP skills. In this study, data on in-service training was collected based on the respondents' statements, but it would have been more appropriate to consult the Ministry of Health's training database. This database, if it exists, would allow for better planning of training for the benefit of health care providers, for more efficient decision-making. In addition to the quantity of in-service training received, it is important to look at its quality, which can be affected by the level of qualification of the trainers. Finally, providers' motivations for training are often varied and still do not always aim at the acquisition of knowledge and skills.

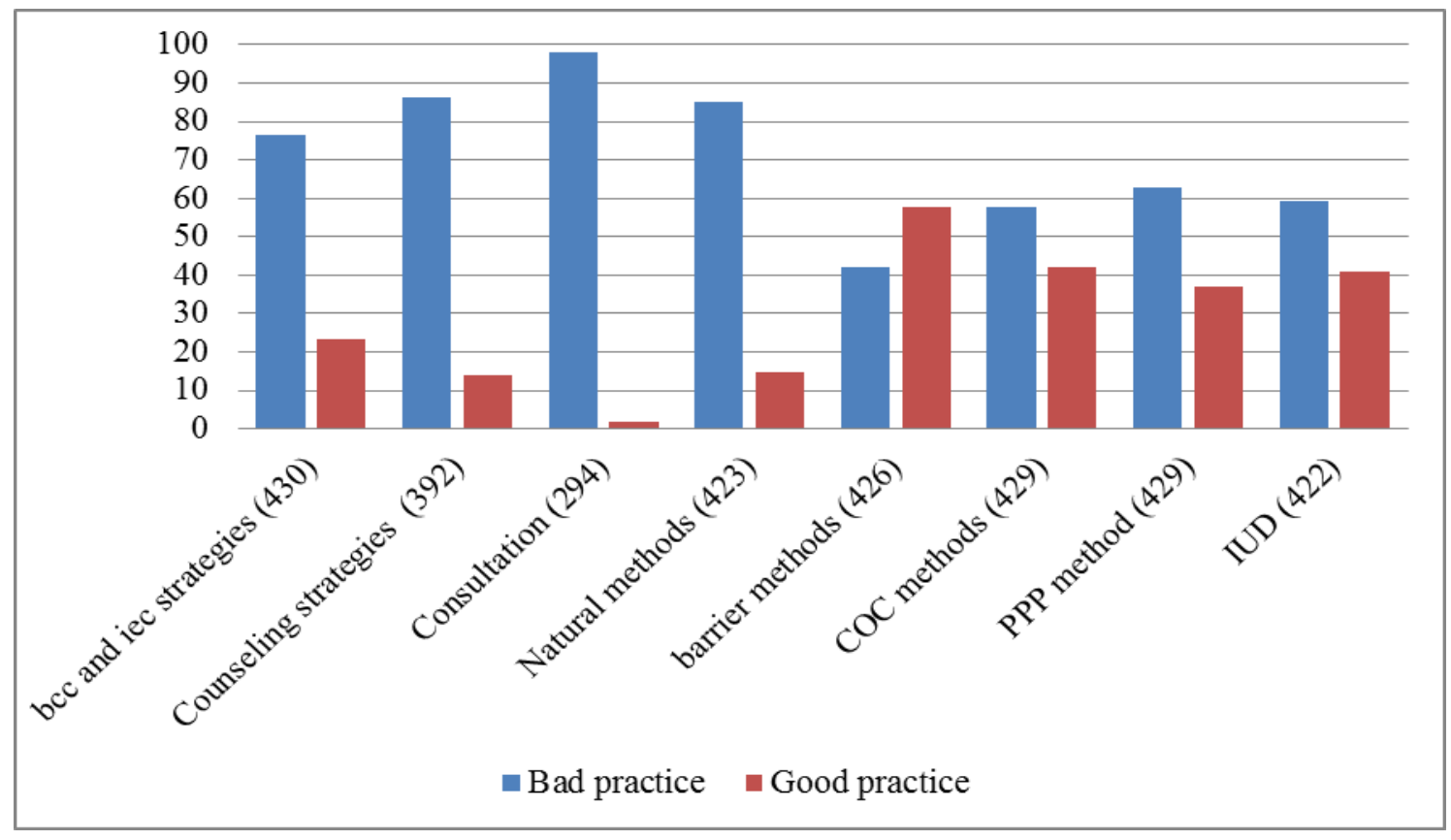

Figure 4. Distribution (\%) of respondents according to their practice of FP methods in Benin in 2019 
The negative attitude of providers towards the systematic recommendation of FP in various circumstances and the management of FP-related side effects, as well as the low level of FP practice, reflect the low quality of FP services in health facilities. However, according to the service-delivery approach, improving the quality of reproductive health services contributes to their utilization [14]. Based on this approach, the results of this study could explain in part the low utilization of FP. Indeed, twelve (12) studies showed that FP use is limited by the perceived side effects of hormonal contraceptive methods, particularly disruption of the menstrual cycle, metrorrhagia, and fear of infertility $[9,15,16]$. To improve FP use, these sometimes misrepresented or rumoured beneficiary claims deserve to be dispelled through proper management of FP-related side effects and IEC to change perceptions and behaviours. However, if providers have poor KAP of FP, strategies such as product safety, awareness campaigns and free FP can only be ineffective.

Beneficiaries' negative attitudes [7, 17], which explain the low utilization of FP, may be justified by the results of this study, especially since FP knowledge and practices will determine compliance with RH/FP guidelines and the satisfaction of FP needs [14]. Strategies for reducing unmet need for FP should therefore also focus on health providers, rather than on beneficiaries.

Benin has made the promotion of FP a national priority, as part of the reduction of maternal and infant mortality. In addition to preventing deaths, increasing contraceptive use would contribute to controlled fertility and poverty reduction in a global perspective [18]. Benin's projections in the Millennium Development Goals (MDGs) were to achieve a modern contraceptive prevalence of $15 \%$ in 2015 and $20 \%$ in 2018. To this end, a program to integrate FP into the reproductive health $(\mathrm{RH})$ services package was implemented with the involvement of civil society. A few years later, the modern contraceptive prevalence rate only slowly increased from $8 \%$ in 2006 to $12 \%$ in 2017-2018 [8, 19]. However, the causes of this gap are largely attributed to demand. While unmet need for FP is still around 30\%, the supply side of the FP gap should also be considered. Our results suggest that FP clients are not receiving adequate information on the full range of contraceptive methods available or on the management of FP-related side effects. These findings had been highlighted by recent work in Benin [19]. In addition to knowledge problems, personal morality and fear of overwork are also factors that can influence the quality of FP services. A study in Ghana found that restrictive behaviours that impose the personal morality of providers on some FP clients hindered their access and violated their human rights [20]. Similarly, as reported by Lantis et al., a study involving 54 nurses, midwives and auxiliary workers in India on the quality of health care in general revealed their limited knowledge [21]. Indeed, while they blamed the failure of health infrastructure and equipment, these providers were not able to define what is considered "quality of health care," nor to describe the extent to which FP services could be improved. The results are also consistent with those obtained regarding the assessment of knowledge and practice of 29 nurses in family planning counselling in health centres city of Lattakia [22]. When providers are known to play an important role in identifying and meeting clients' health care needs, their KAP can have a significant impact on clients' perceptions of the services available to them. The fear of workload may also underlie some poor care behaviours among providers. This may explain why some clients perceive the quality of care to be poor [23]. With the increasing population growth in sub-Saharan Africa, FP should be understood as a development priority for any country [24]. Similarly, sexual and reproductive health rights (SRHR), now an integral part of Universal Human Rights, are binding on all States, which must take the measure of the stakes and integrate them into their development programs. Benin has demonstrated its political commitment to promote FP by acquiring a legal arsenal and an institutional framework. However, avoidable obstacles persist and particularly affect FP service providers, for whom the KAP is paramount. In view of the above, in addition to the actions deployed in the field to boost demand, special emphasis could be placed on reviewing existing FP policies and programmes, including the improvement of services and training, and capacity building of care providers' KAP on the quality of FP care and services in particular.

The present study, which covered all levels of the health care system and all types of health structures, provides a national overview on KAP in the area of FP in Benin. However, there are limitations related in particular to the mode of data collection, which concern the need of soliciting the verbal reaction of respondents in fictitious or symbolic situations. The KAP questionnaire was not administered to gynaecologists because they are trainers and supervisors of other professional categories (midwives, nurses, health care assistants) in FP services. This consideration may also be a limitation because these physicians may also have gaps in FP KAP. The evaluation of their KAP in the area of FP would have made it possible to justify the shortcomings observed at the health provider level and to identify possible gaps that need to be filled. However, beyond this limit, the results of this study constitute an important inventory that will be used to redirect efforts for better FP coverage in Benin.

\section{Conclusions}

This study aimed to examine the knowledges, attitudes and practices of health providers in line with the standard guidelines as far as FP in Benin. Results showed that slightly more than half of the respondents had an extended knowledges of FP methods. This lack of knowledges 
resulted in inadequate attitudes and practices in regard to the standard guidelines in FP. Unlike the unavailability of FP supplies which usually pointed out to explain the low performance of services, the current study revealed important gaps in knowledges, attitudes and practices among health providers in regard to the recommended guidelines in FP. There is, therefore, a need for public policy makers to propose, in addition to current and existing interventions, basic training programs in Sexual and Reproductive Health Rights (SRHR) as part of training packages toward providers with low KAP in FP. It is also important to envisage capacity strengthening interventions based on professional qualification toward those with good KAP. Formative supervision also constitutes a great strategy for quick assimilation of acquired knowledges from trainings.

\section{Authors' contributions}

Jacques Saïzonou: Substantial contributions to the conception of the work, the acquisition, analysis and interpretation of data; revising it critically for important intellectual content

Alphonse M. Affo: Substantial contributions to the conception of the work, the acquisition, analysis and interpretation of data; Drafting the work; revising it critically for important intellectual content

Virginie Mongbo: Substantial contributions to the acquisition of data; Drafting the work; revising it critically for important intellectual content

Edgard-Marius Ouendo: Substantial contributions to the conception of the work
Patrick Makoutodé: Substantial contributions to the conception of the work, the acquisition, analysis and interpretation of data

Alphonse Kpozèhouen: Substantial contributions to the analysis and interpretation of data

Robert Zannou: Substantial contributions to the conception of the work; revising it critically for important intellectual content

Thierry Tossou Boco: Substantial contributions to the conception of the work; revising it critically for important intellectual content

Soulemane Zan: Substantial contributions to the conception of the work; revising it critically for important intellectual content

Léopold Ouédraogo: Substantial contributions to the conception of the work; Final approval of the version to be published

\section{Acknowledgments}

We would like to acknowledge the technical support of the Ministry of Health of Benin and to the Regional Public Health Institute and the technical support and funding of the World Health Organization.

\section{Disclosures about potential conflict of interests}

No conflict of interests. All parties agreed to the publication of the article and contributed to its writing. 


\section{Appendix}

\section{Screenshots for Statistical Analyses (selected)}

困 Stata/SE 16.0 - C:IUsers VDANSOUIDesktop \AffolManuscript-PF\Base_CAP_OMSrevue.dta File Edit Data Graphics Statistics User Window Help

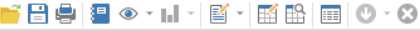

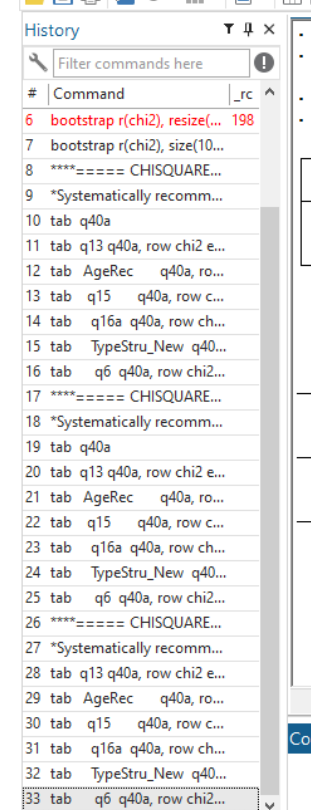

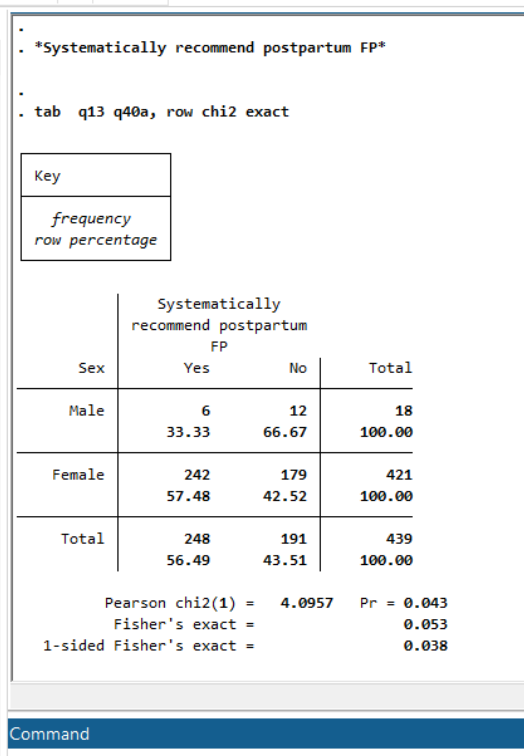

C: Users VDANSOU Desktop \AffolManuscript-PF
围 Stata/SE 16.0 - CilUsers UDANSOUIDesktop \AffolManuscript-PFIBase_CAP_OMSrevue.dta File Edit Data Graphics Statistics User Window Help

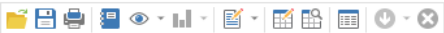

History

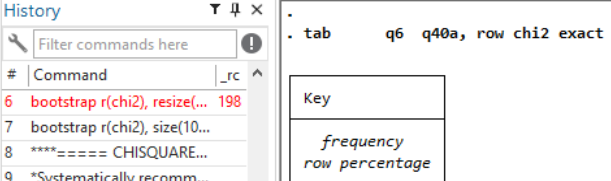

* *ystematically recomm.

10 tab q40a

11 tab q13 q40a, row chi2 e...

12 tab AgeRec $q 40$ a, ro...

13 tab q15 q40a, row c....

14 tab q16a q40a, row ch...

15 tab TypeStru_New q40...

16 tab q6 q40a, row chiz...

$17 * x+x=====$ CHISQUARE...

18 *Systematically recomm...

19 tab q40a

20 tab q13 q40a, row chi2 e..

21 tab AgeRec q40a, ro...

22 tab q15 q40a, row c...

23 tab q16a q40a, row ch...

24 tab TypeStru_New q40...

25 tab q6 q40a, row chiz...

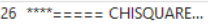

27 *Systematically recomm....

28 tab q13 q40a, row chize.

29 tab AgeRec q40a, ro...

30 tab q15 q40a, row c...

31 tab q16a q40a, row ch...

32 tab TypeStru_New q40...

33 tab q6 q40a, row chiz....

\begin{tabular}{r|rr|r}
$\begin{array}{r}\text { Place of } \\
\text { residence }\end{array}$ & \multicolumn{3}{|c}{$\begin{array}{r}\text { Systematically } \\
\text { recommend postpartum } \\
\text { FP }\end{array}$} \\
\hline Yes & No & Total \\
\hline Rural & 174 & 127 & 301 \\
& 57.81 & 42.19 & 100.00 \\
\hline Urban & 72 & 57 & 129 \\
& 55.81 & 44.19 & 100.00 \\
\hline Total & 246 & 184 & 430 \\
& 57.21 & 42.79 & 100.00
\end{tabular}

Pearson $\operatorname{chi} 2(1)=0.1466 \mathrm{Pr}=0.702$ $\begin{array}{rrr}\text { Pearson chi2 }(1) & =0.1466 & \mathrm{Pr}=0.702 \\ \text { Fisher's exact }= & 0.750 \\ \text { 1-sided Fisher's exact }= & & 0.390\end{array}$

0.390

C:IUsers UDANSOU\Desktop \Affo $\backslash$ Manuscript-PF

\section{A 0 ○}

田 Stata/SE 16.0 - C: U Users VDANSOUIDesktoplAffolManuscript-PF/Base_CAP_OMSrevue.dta

File Edit Data Graphics Statistics User Window Help

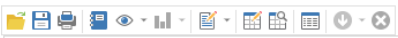

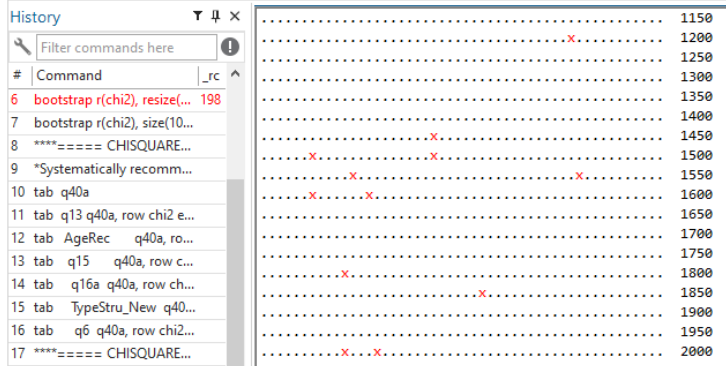

17 .

18 *Systematically recomm.

19 tab q40a

20 tab q13 q40a, row chize.

21 tab AgeRec q40a, ro...

22 tab q15 q40a, row c...

23 tab q16a q40a, row ch...

24 tab TypeStru_New 940 .

25 tab 96 q40a, row chi2...

$26^{*}====$ CHISQUARE..

27 *Systematically recomm...

28 tab q13 q40a, row chi2 e.

29 tab AgeRec q40a, ro.

30 tab q15 q40a, row c...

31 tab q16a q40a, row ch.

32 tab Typestru New 940.

33 tab 96 q $40 a$, row chiz...

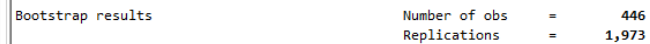

command: tabulate q13 q40a, row chi2 exact

_bs_1: $\quad r$ (chi2)

\begin{tabular}{r|rlcccc}
\hline & $\begin{array}{r}\text { Observed } \\
\text { Coef. }\end{array}$ & $\begin{array}{l}\text { Bootstrap } \\
\text { Std. Err. }\end{array}$ & $z$ & $P>|z|$ & \multicolumn{2}{c}{$\begin{array}{c}\text { Normal-based } \\
\text { [95\% Conf. Interval] }\end{array}$} \\
\hline _bs_1 & 4.09569 & 1.977391 & 2.07 & 0.038 & .220074 & 7.971306 \\
\hline
\end{tabular}

nuscript-PF

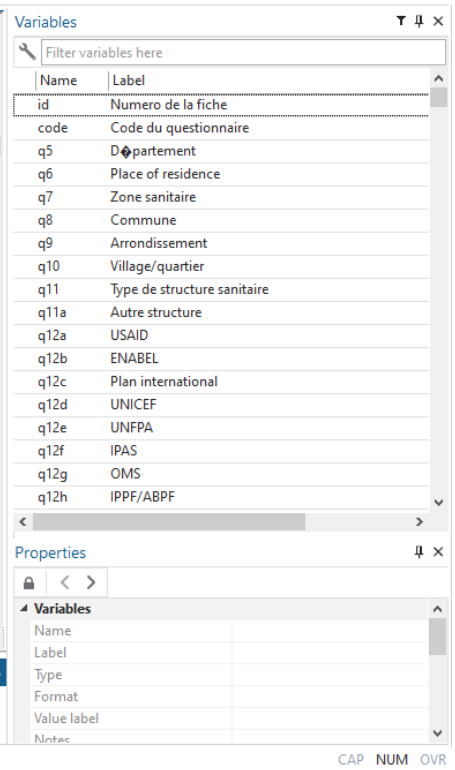




\section{REFERENCES}

[1] World Health Organization, "World health statistics 2015", Available on:, https://reliefweb.int/report/world/world-healt h-statistics-2015 (accessed may 27, 2017).

[2] World Health Organization. Trends in maternal mortality: 1990 to 2013. Estimates by WHO, UNICEF, UNFPA, The World Bank and the United Nations Population Division. [Online]. [Accessed: 24/04/16], Available at: http://apps.who.int/iris/bitstream/10665/112682/2/97892415 07226_eng.pdf, (Accessed April 24, 2016).

[3] Organisation Mondiale de la Santé. "Statistiques sanitaires mondiales 2014. ", [Online]. Available on : 2014http://apps.who.int/iris/bitstream/10665/131954/1/9789 240692688 fre.pdf, (Accessed oct. 24, 2016).

[4] Nations Unies. "Objectifs du Millénaire pour le développement" [Rapport] [Online]. []. Available at: http://www.un.org/fr/millenniumgoals/reports/2015/pdf/rap port_2015.pdf, (Accessed april 24 2016).

[5] Organisation Mondiale de la Santé. "Tendances de la mortalité maternelle : 1990-2015“, [Online]. Available at: https://apps.who.int/iris/bitstream/handle/10665/204113/W HO_RHR_15.23 fre.pdf;jsessionid=D899A228927576F1E 40B46DE94602638? sequence=1, (Accessed April 242016).

[6] N. Prata, A. Sreenivas, F. Greig, J. Walsh, M. Potts. Setting priorities for safe motherhood interventions in resource-scarce settings. Health Policy. Vol. 94 pp. 1-13, 2010, DOI: 10.1016/j.healthpol.2009.08.012.

[7] S. Hogmark, M. Klingberg-Allvin, K. Gemzell-Danielsson, H. Ohlsson, B. Essén. Medical students' knowledge, attitudes and perceptions towards contraceptive use and counselling: a cross-sectional survey in Maharashtra, India. "BMJ open", Vol. 3, No. 12, 2013, DOI:10.1136/bmjopen-003739 .

[8] Institut National de la Statistique et de l'Analyse Economique. Enquête Démographique et de santé (EDSB-V) 2018 [Online]. [Accessed on 14/06/19]. Available at: https://www.google.com/?hl=fr\&gws_rd=ssl\#hl=fr\&q=+En qu $\%$ C3\%AAte $+D \% C 3 \%$ A 9 mographique + et + de + sant $\%$ C3 \%A9+\%28EDSB-V\%29+2011-(Accessed june 14, 2019).

[9] K. Machiyama, J. C. Cleland. 2013 "Analyse des besoins non satisfaits au Sénégal", Rapport de Recherche STEP UP. London: London School of Hygiene \& Tropical Medicine. https://knowledgecommons.popcouncil.org/departments_sbs r-rh/276/, DOI: 10.31899/rh4.1059.

[10]Ministère de la Santé. Stratégie nationale de repositionnement de la planification familiale au Bénin 2011-2015, Cotonou, 54p, 2010.

[11]T. Ritter, A. Dore, K. McGeechan. "Contraceptive knowledge and attitudes among 14-24-year-olds in New South Wales, Australia", Australian and New Zealand journal of public health, Vol. 39, No. 3, pp 267-269, 2015, DOI: $10.1111 / 1753-6405.12367$.

[12] Organisation Mondiale de la Santé, Ministère de la Santé du Bénin. Evaluation des connaissances, attitudes et pratiques des prestataires des 34 Zones sanitaires sur les soins d'avortements sécurisés et la planification familiale au Bénin. Cotonou, 85p, 2019.

[13] Ministère de la Santé du Bénin. Protocoles des services de santé familiale. Composantes communes. Cotonou, 167p, 2018.

[14] M. J. Essi, O. Njoya. L'enquête CAP en recherche médicale. "Health Sciences and Diseases"; Vol. 14, No 2, 2013, URL: https://www.hsd-fmsb.org/index.php/hsd/article/view/183.

[15] A. M. Affo, R. Y. Djogbenou, J. D. G. Avakoudjo, C. Degbey, J. Saizonou, P. Acotcheou, and J. Dansou, Influence de l'homme sur les Besoins non satisfaits en matière de planification familiale (BNS/PF) chez les femmes en union au Bénin, "International Journal of Innovation and Applied Studies". Vol. 27, No 2, pp. 654-72, 2019, http://www.ijias.i ssr-journals.org/.

[16] L. M. Williamson, A. Parkes, D. Wight, M. Petticrew, G. J. Hart. Limits to modern contraceptive use among young women in developing countries: a systematic review of qualitative research. "Reproductive health", Vol. 6, No. 3, 12p. 2009. DOI:10.1186/1742-4755-6-3.

[17] C. M. Matungulu, S. I. Kandolo, A. N. Mukengeshayi, A. M. Nkola, D. I. Mpoyi, S. K. Mumba, J. N. Kabamba, K. Cowgill, and F M. Kaj, Déterminants de l'utilisation des méthodes contraceptives dans la zone de santé Mumbunda à Lubumbashi, République Démocratique du Congo. "Pan African Medical Journal", Vol. 22, No. 1, 2015, URL: https://www.panafrican-med-journal.com/content/article/22/ 329/full DOI:10.11604/pamj.2015.22.329.6262.

[18] N. Prata, K. Weidert, A. Sreenivas. Meeting the need: youth and family planning in sub-Saharan Africa. "Contraception". Vol. 88, pp. 83-90, 2013, DOI: 10.1016/j.contraception.201 2.10.001.

[19] S. Chae, V. Woog, C. Zinsou, M. Wilson. Obstacles à la pratique contraceptive des femmes au Bénin. [rapport]. [Online]. []. Available at: http://www.guttmacher. org/pubs/IB-Benin-contraception-fr. Html, (Accessed jan. 13, 2020).

[20] Ministère de la Santé, République du Bénin, Direction de la Santé de la Mère et l'Enfant, Plan d'action national budgétisé pour le repositionnement de la planification familiale 2014 2018 au Bénin/ Cotonou : 2013

[21] J. Stanback, K. A. Twum-Baah. Why Do Family Planning Providers Restrict Access to Services? An Examination in Ghana. "International Perspectives on Sexual and Reproductive Health", Vol 27, No 1, pp. 37-41, 2001, DOI, https://doi.org/10.2307/2673804

[22] A. R. Manal \& al. Assessment of the Knowledge and Practice of Nurses about Family Planning Counseling in Health Care Centers - Lattakia. Universal Journal of Public Health 8(4): 148-154, 2020. https://doi.org/10.13189/ujph.2020.080406.

[23] K. Lantis, C. P. Green, S. Joyce. Prestataires et qualité des soins. Nouvelles perspectives sur la qualité des soins. Vol. 3, pp. 1-8, 2002, URL:https://www.prb.org/wp-content/upload s/2002/07/QOC3Providers_Fr.pdf

[24] M. Niang, S. Dupéré, E. Bédard. Le non-recours aux soins prénatals au Burkina Faso, "Santé Publique".Vol. 27, pp. 405-414, 2015, https://doi.org/10.3917/spub.153.0405. 